Araştırma Makalesi

\title{
Sahil ve Kırsal Bölge İkileminde Mekân Değişikliğinin Üniversite Öğrencilerinin Yaşam Doyumuna Etkisi: Kapadokya MYO Örneği
}

\section{Hasan Gülüpunar (Prof. Dr.)}

(iD) Süleyman Demirel Üniversitesi Illetişim Fakültesi hgullupunar@gmail.com Merve Özdemir (Öğr. Gör.)

(iD) Kapadokya Üniversitesi Kapadokya Meslek Yüksekokulu merve.ozdemir@kapadokya.edu.tr

Başvuru Tarihi: 02.04.2020

Yayına Kabul Tarihi: 23.05.2020

Yayınlanma Tarihi: 24.07.2020

https://doi.org/10.17680/erciyesiletisim.713023

\section{Öz}

Türkiye'nin sahil bölgelerinden iç bölgelerine gelmiş olan üniversite öğrencileri, coğrafi değişkenlerin yanı sıra, üniversite yaşantısı, bölge halkı ile kurulan iletişim, sosyalleşme, ulaşım, değişen iklim koşulları gibi birçok faktör bakımından uyum göstermek gibi bir durumla karşı karşıya kalmaktadır. Bu çalışmada üniversite öğrencilerinin yaşam doyumu düzeylerinin, iç bölgelerle ilgili bahsedilen bu hususlara dayalı olarak nasıl etkilendiğinin ele alınması amaçlanmaktadır. Araştırmanın örneklemi, Kapadokya Üniversitesi Meslek Yüksekokulunun çeşitli bölümlerinde öğrenimlerine devam eden ve Türkiye'nin sahil bölgelerinden Kapadokya'ya gelmiş 92 öğrenciden oluşmaktadır. Öğrencilerin yaşam doyumu düzeyini belirlemek amacıyla Diener'in (1985) yaşam doyumu ölçeği kullanılmıştır. Yapılan Doğrulayıcı faktör analizinde araştırma verilerinin yaşam doyumu ölçeğiyle uyumlu olduğu görülürken; keşfedici faktör analizinde ise öğrencilerin bölge, șehir ve üniversiteye olan algıları "üniversite", "yeme-içme”, "yerli halk", "mimari yapı" ve "şehir" boyutlarıyla tanımlanmıştır. Araştırma sonuçları "üniversite" faktörünün öğrencilerin yaşam doyumları üzerinde pozitif yönlü anlamlı bir etken olduğunu gösterirken; "yeme-içme", "mimari yapı", "yerli halk" ve "şehir" faktörlerinin ise anlamlı bir etken olmadığını göstermiştir.

Anahtar Kelimeler: Yaşam doyumu, mutluluk, üniversite, Kapadokya Üniversitesi.

Bu çalışma, Kapadokya Üniversitesi Bilimsel Araştırmalar ve Yayın Etiği Kurulu'nun 1.04.2019 tarihli toplantısında görüşülmüş ve gerçekleştirilmesinde etik ve bilimsel sakınca bulunmadığına oy birliği ile karar (2019.03) verilmiş̧ir. 


\section{The Effect of Change of Place Between The Dilemma of Coast and Rural Area on Students' Life Satisfaction: The Case of Cappadocia Vocational High School}

\section{Hasan Güllüpunar (Prof. Dr.)}

iD Süleyman Demirel University Faculty of Communication hgullupunar@gmail.com Merve Özdemir (Lect.)

(iD) Cappadocia University Cappadocia Vocational College merve.ozdemir@kapadokya.edu.tr

Date Received: 02.04.2020

Date Accepted: 23.05.2020

Date Published: 24.07.2020

https://doi.org/10.17680/erciyesiletisim. 713023

\section{Abstract}

Students who have arrived from coastal areas to hinterlands face not only geographical change but are also exposed to college life, relation with the local community, socializing, transportation, and different weather conditions. This study will focus on the examination of how life satisfaction levels of university students are affected based on the location. The research sample consists of 92 students who continue studying in various departments at the Cappadocia Vocational School. The data was accessed from the administration of Satisfaction with Life Scale developed by Diener (1985). In the confirmatory factor analysis conducted, it was seen that the research data were compatible with the life satisfaction scale; in the exploratory factor analysis, students' perceptions of the region, city and university were defined with the dimensions of "university", "food and drink", "local people", "architectural structure" and "city". Whereas research results show that the "university" factor is a positive and significant factor on students' satisfaction with life; it showed that the elements of "food and drink", "architectural structure", "local people" and "city" are not significant factors.

Keywords: Life Satisfaction, Happiness, University, Cappadocia University. 


\section{Giriş}

Günümüzde artarak devam eden pozitif psikoloji çalışmaları, insan psikolojisinin anlaşılması için önemli gelişmeleri gündeme getirmektedir. Son 60 yıldır psikoloji biliminin "hasarı tamir etmek" için bir şey yapma telaşı içerisinde olduğunu vurgulayan Seligman, insanları daha mutlu kılacak olumlu yöntemlerin geliştirilmesi gerektiğini önemle belirtmektedir (Seligman, 2012). Bu noktada Seligman, insanın zayıf tarafları ile ilgilenildiği kadar güçlü tarafları ile de ilgilenilmesi gerektiğini vurgulamaktadır (Seligman, 2012). Psikolojinin ilk yıllarında üzerine sıklıkla çalışılan depresyon, kaygı ve stres gibi olumsuz duygu çalışmalarına karşılık ortaya çıkan pozitif psikoloji araştırmaları, mutluluk, yaşam doyumu ve iyi oluş gibi kavramları psikolojinin temel araștırma konuları haline getirmiştir (Myers, 1993, s. 15). İnsanların hayattaki tatmin seviyelerini yükseltmek, yaşam doyumlarını arttıracak çözüm önerileri getirmek, son 10 yıldır geliştirilmeye başlanan pozitif psikolojinin konuları arasında yer almaktadır (Seligman, 2012). Bilimsel olarak pozitif psikoloji çalışmaları sonradan literatüre girmiş olsa da Antik Yunan düşünürleri tarafından sıklıkla tartışılan bir konu olmuştur. Mutluluğun yavaş, acelesiz ve akıllıca bir yaşamdan geçeceğini öne süren Antik Yunan filozofları (Myers, 1993, s. 16) insan aklının temel olarak merkez alınması gerektiğini belirtmişlerdir. Genel olarak kendimizi mutlu olarak tanımlayabilir miyiz? Bu sorunun cevabını Myers farklı görüşler üzerinden şu şekilde açıklamaktadır: Freud'a göre acılarımızı baskılayıp mutlu olduğumuzu söylemek kendimizi aldatmaktan başka bir şey değildir. Marx’a göre ise bizler yanlış bilinç ile adaletsizliğin acısından kurtulmaktayız. Dolayısıyla mutluluk insanda süreklilik arz eden bir duygu değildir. Sıklıkla ruh durumunu mutlu olarak ifade eden kişilerin toplumda psikolojik olarak sorunlu bireyler olarak nitelendirildiği ve kişilerin bu durumdan utandığı için kendilerini mutlu olarak ifade edemediği görülmektedir (Myers, 1993, s. 26-27).

Mutluluk ve yaşamdan memnuniyet gibi kavramlar insanın kendi algılamasına göre, istedikleri ile sahip oldukları arasındaki farkın ne kadar az olduğu ile ilgilidir. Genellikle beklentilerin yükselmesi bu iki kavram arasındaki farkı arttırarak (Csikszentmihalyi, 2005, s. 277) öznel iyi oluş kavramını olumsuz yönde etkilemektedir. Öznel iyi oluş, sıklıkla pozitif etkinin var olması ve yaşamdan genel olarak memnuniyet duyulmasını ifade etmektedir. Olumlu-olumsuz duygulanım ve yaşam doyumu gibi kavramlar öznel iyilik halinin içerisinde yer almaktadır. Kaygı, depresyon, sevinç, üzüntü, keder gibi duygular olumlu-olumsuz duygulanımı ifade ederken, kişinin iş, evlilik ve özel hayatına dair genel yaşam doyumu ise iyilik halinin bilişsel boyutunu temsil etmektedir (Myers \& Diener, 1995, s. 10-11). "Memnuniyet mutluluğun en önemli bileşenlerinden biridir. Mutluluk bireyin duygusal yanına, memnuniyet ise bilişsel tarafına karşlılk gelmektedir" (Argyle, 2001, s. 39). Buradan da anlaşılacağ gibi yaşam doyumu ve kendini iyi hissetme kavramları duygusal ve bilişsel süreçlerden bağımsız değildir.

Almanca'da, bireyin çok boyutlu dünya algısına karşılık gelen weltbild ${ }^{1}$ sözcügü aynı olayın her birey tarafından farklı olarak algılandığını ortaya koymaktadır. Dolayısıyla birey, sahip olduğu bu özel algı sayesinde düşünce ve davranış örüntülerini geliștirmekte; sosyal, kültürel, politik, dini ve ekonomik birçok olguyu kendi özel dünyası içerisinde anlamlandırmaktadır. Kişisel inşa kuramı üzerinden de açıklanacak olan bu durum bireylerin algılama süreçlerinin, sahip oldukları psikolojiden bağımsız olmadığını göstermektedir (Kelly, 2003, s. 4-7). Bu anlamda yaşam doyumunu ölçümleyebilmek için kişinin düşünce sisteminin yanında eyleme yönelik davranışsal eğilimleri de incelemeye alınmalıdır. Bir kişi ya da kişiler topluluğunun zihinsel durumunu kişisel inşa kuramındaki 
süreçlerden yola çıkarak da incelemek mümkündür. Bu sayede kişilerin kendilerini çevreleyen mekâna ve kişilere karşı takındıkları tavırları, algılama ve yorumlama süreçlerini tespit etmek davranış örüntülerini anlamada kolaylık sağlayacaktır.

Kişinin iyi oluşu yaşam doyumunun ölçülmesinde ve yaşam kalitesinin araştırılmasında önemli bir faktördür. Bahsedilen doyum alanları ise toplumsal, sosyal, ekonomik, kültürel ve coğrafik koşullardan bağımsız değildir. Fenomenolojik düşünce akımının da üzerinde durduğu bu koşullar, insan davranışlarını anlamada ve açıklamada önemli bir rol oynamaktadır. Varoluşçuluk ve idealizm gibi farklı felsefi akımlardan beslenen ve köken olarak hermenotik yaklaşıma dayanan bir paradigma olan fenomenolojik yaklaşım, (Kaya, 2014, s. 29) konumuzdaki bağlamların fiziki mekân üzerinden daha detaylı incelenmesine dayanak oluşturmaktadır. Kişinin yaşam doyum süreçlerini anlayabilmek için çok yönlü bir sentez yapılmasına katkı sağlayan bu düşünce yaklaşımı, insanın karmaşık zihin dünyasını açıklamak ve çözüm önerileri geliştirmek için insanı çalışmaların merkezine koymuştur.

İnsanın duygu ve düşünce dünyasının karmaşık olduğunu vurgulayan fenomenolojik yaklaşım, davranışçı yaklaşımın mekanik anlayış ile insan davranışlarını açıklamasına karşı çıkar. Fenomenolojik yaklaşım insan değerlerinin anlaşılması gerektiği üzerine değinerek gündelik hayata, fiziki mekâna, sosyal ve kültürel çevrenin insan davranışları üzerindeki etkisine önem verir (Kaya, 2014, s. 29-32). Bu anlamda insan davranışlarının yorumlanması ve bireye özgü algılayışın ortaya konulması fenomenolojik yaklaşımın en temel konularından birisidir (Tutar, 2018, s. 47). Kişilerin bulunduğu mekân ile aidiyet kurması ve bulunduğu mekandaki insanlarla ilişki geliştirmesi yaşam doyumu ölçümünde belirleyici bir role sahiptir. Bir toplumdaki bireyleri çevreden, toplumdan, ekonomiden ve coğrafyadan bağımsız değerlendirmek, oluşturulacak sonuçların yanlış veya eksik kalmasına sebep olabilir. Dolayısıyla, kişinin içerisinde yaşadı̆̆ içsel durumlar, bulunduğu çevreye, kişilere ve olaylara bakış açısını da belirleyebilmekte ve yaşam doyumunu bu yönde şekillendirebilmektedir. Çalışmanın araştırma kısmında üniversite öğrencileri üzerinden örneklendireceğimiz yaşam doyumu, öğrencilerinin iyi oluş noktalarını geliştiren durumların belirlenmesi ve uygulanması açısından önem taşımaktadır. Bu araştırmayla Kapadokya'daki üniversite öğrencilerinin yaşam doyumu düzeyine etki eden faktörler belirlenerek çeşitli iyileştirici çalışmaların yapılabilmesi açısından birtakım öneriler geliştirilebilecektir.

\section{Araştırma Soru ve Hipotezleri}

Türkiye'nin sahil boylarında ikamet edip üniversite öğrenimlerini tamamlamak üzere iç bölgelere giden öğrencilerin yaşam doyumları üzerine yapılan bu araştırmanın araştırma sorusu şu şekilde belirtilmiştir:

- Sahil yerleşim birimlerinden gelerek kırsal bir bölgede üniversite öğrenimlerini sürdüren öğrencilerin şehir/bölge ve üniversiteye olan algıları hangi boyutlarla tanımlanabilir?

Araştırmanın hipotezleri ise aşağıdaki gibi sıralanmıştır:

\section{Araştırma hipotezi 1}

$\mathrm{H}_{0}$ Araştırmaya katılan öğrencilerin şehir, bölge ve üniversiteye olan algıları yaşam doyumlarını etkilemez.

$\mathrm{H}_{1}$ Araştırmaya Katılan öğrencilerin şehir, bölge ve üniversiteye olan algıları yaşam doyumlarını etkiler. 


\section{Araştırma hipotezi 2}

$\mathrm{H}_{0}$ Araştırmaya katılan öğrencilerin cinsiyetleri ile şehir, bölge ve üniversiteye olan algıları arasında anlamlı bir fark yoktur.

$\mathrm{H}_{1}$ Araştırmaya katılan öğrencilerin cinsiyetleri ile şehir, bölge ve üniversiteye olan algıları arasında anlamlı bir fark vardır.

\section{Araştırma Hipotezi 3}

$\mathrm{H}_{0}$ Araştırmaya katılan öğrencilerin aylık harcama miktarı ile şehir, bölge ve üniversiteye olan algıları arasında anlamlı bir fark yoktur.

$\mathrm{H}_{1}$ Araştırmaya katılan öğrencilerin aylık harcama miktarı ile şehir, bölge ve üniversiteye olan algıları arasında anlamlı bir fark vardır.

\section{Araştırma Hipotezi 4}

$\mathrm{H}_{0}$ Araștırmaya katılan öğrencilerin ikamet biçimleri ile şehir, bölge ve üniversiteye olan algıları arasında anlamlı bir fark yoktur.

$\mathrm{H}_{1}$ Araştırmaya katılan öğrencilerin ikamet biçimleri ile şehir, bölge ve üniversiteye olan algıları arasında anlamlı bir fark vardır.

\section{Araştırma Hipotezi 5}

$\mathrm{H}_{0}$ Araştırmaya katılan öğrencilerin üniversiteye gelmeden önceki yaşadıkları yer ile şehir, bölge ve üniversiteye olan algıları arasında anlamlı bir fark yoktur.

$\mathrm{H}_{1}$ Araştırmaya katılan öğrencilerin üniversiteye gelmeden önceki yaşadıkları yer ile şehir, bölge ve üniversiteye olan algıları arasında anlamlı bir fark vardır.

\section{Metodoloji}

Çalışmada öğrencilerin şehir, bölge ve üniversiteye olan algılarıyla ilgili boyutların tanımlanması ve yaşam doyumu ölçeğinin doğrulanması bakımından keşfedici araştırma modeli; araştırmaya katılanların demografik özellikleri ile şehre, bölgeye ve üniversiteye dönük algıları arasındaki farklılıkların tanımlanması açısından tanımlayıcı araştırma modeli ve öğrencilerin şehir, bölge ve üniversiteye olan algılarının yaşam doyumları üzerindeki etkisinin araştırılması için neden sonuç ilişkisi belirten araştırma modeli kullanılmıştır. Keşfedici araştırma modeli araştırma probleminin saptanması, probleme ilişkin değişken ve boyutların belirlenmesi amacına hizmet eden bir modeldir. Tanımlayıcı araştırma modeli değişken ve değișkenler arasındaki ilişkileri tanımlamak ve bu tanımlamaya dayanarak ileriye dönük tahminler yapmak için kullanılmaktadır. Neden sonuç ilişkisi belirten araştırma modeli ise iki veya daha fazla değişken arasındaki etki, neden sonuç bağlantısını tanımlamayı amaçlayan araştırmalardır (Kurtulmuş, 2006, s. 19-21).

\subsection{Araştırmanın Uygulanması ve Örneklem}

Araștırma Kapadokya Üniversitesi Kapadokya Meslek Yüksekokulunda gerçekleştirilmiştir. Kapadokya Meslek Yüksekokulunda 29 sınıfta toplam 524 öğrenci bulunmaktadır. Araştırma yapılacak sınıflar amaçlı örneklem yöntemiyle 11 sınıf olarak belirlenmiştir. Öğrencilerinin yaşam doyumlarının tanımlanmasında Üniversitenin bulunduğu şehirde daha fazla yaşam sürenlerin önemli olduğu varsayımından hareketle üst sınıflar örnekleme alınmıștır. Dolayısıyla araştırmada örneklem olarak 2. Sınıflar seçilmiştir. Örneklem için ulaşılan bu sınıflarda ise öğrencilere Türkiye'nin sahil bölgelerinden gelip gelmedikleri sorulmuş ve sahil bölgelerinden gelen öğrencilerle araştırma gerçekleştirilmiştir. Bu yolla toplam 92 öğrenciye ulaşılmıştır. Dolayısıyla 524 öğrencinin 92'si ile görüşme yapılmıştır. 


\subsection{Veri Toplama Araçları}

Araştırma soru formunun birinci bölümü Diener (1985) tarafından genç yaş grupları için geliştirilen yaşam doyumu ölçeğinden oluşmaktadır. Bu ölçek 5 maddeden oluşmakta ve cevap seçeneğinde 1'den 7'ye giden 7 dereceli bir cevap kategorisi bulunmaktadır. Ölçekte "hiç uygun değil" 1 , "uygun değil" 2 , "biraz uygun değil" 3, "ne uygun ne de uygun değil" 4, "biraz uygun" 5, "uygun" 6, "çok uygun" 7 șeklinde değerler alınmaktadır (Köker, 1991, s. 41). Bu çalışmada sahil boylarında okuyan öğrencilerin örnekleme alınması ve bu sayının az olması nedeniyle 7 dereceli cevap kategorisi yerine Likert tipi 5 dereceli cevap kategorisi kullanılmıştır. Ölçeğin maddelerinin Türkçeye çevrilmiş hali ise "Yaşamım birçok yönüyle ideallerime yakın., "Yaşam koşullarım çok iyi.", "Yaşamımdan hoşnutum.,", "Şu ana kadar istediğim şeyleri elde edebildim." ve "Yeniden Dünyaya gelseydim yaşamımda hemen hemen hiçbir şeyi değiştirmezdim." şeklindedir (Köker, 1991, s. 71).

Araştırma soru formunun ikinci bölümü araştırmaya katılan öğrencilerin üniversitenin bulunduğu şehre, bölgeye ve üniversiteye olan algılarının tanımlanması amacıyla hazırlanan bir ölçekten oluşmaktadır. Ölçekte cevaplar 5'li Likert ölçeğiyle alınmıştır. Ölçekte toplam 46 madde bulunmaktadır. Hem bu maddelere alınan cevaplar hem de yukarıda belirtilen yaşam doyumu ölçeğine alınan cevaplar "kesinlikle katılmıyorum" 1 , "katılmıyorum" 2, "ne katılıorum ne de katılmıyorum" 3, "katılıyorum" 4 ve "kesinlikle katılıyorum" 5 şeklinde kodlanmıştır. Araştırma soru formunun üçüncü bölümü ise araştırmaya katılanların sosyo-demografik özelliklerinin belirlenmesine dönük olarak hazırlanan kategorik sorulardan oluşmaktadır.

\subsection{Verilerin Analizi ve Kullanılan Testler}

Araştırmada elde edilen veriler SPSS ve AMOS Programlarıyla analiz edilmiştir. Bu bağlamda SPSS programıyla betimleyici istatistikler, ANOVA, Bağımsız Örneklem T-Testi ve Çoklu Regresyon analizleri; AMOS programıly ise Doğrulayıcı Faktör Analizi gerçekleştirilmiştir.

\section{Araştırmanın Bulguları}

\section{1. Betimleyici İstatistikler}

Araștırma Kapadokya Üniversitesi Meslek Yüksekokulunda öğrenimine devam eden ve Türkiye'nin sahil memleketlerinde yaşarken Nevşehir'in Ürgüp İlçesi ve Mustafapaşa köyüne gelen toplam 92 öğrenciyle gerçekleştirilmiştir. Araştırmaya katılanların yüzde 32.6'sı erkek, yüzde 67.4'ü kadındır. Araștırmaya katılan öğrencilerin yüzde 21.7'si ayda 100 ile 600 TL arası harcama yaparken; yüzde 21.7'si 650-800 TL, yüzde 20.7'si 8501100 TL, yüzde 25'i 1200-1800 TL ve Yüzde 10.9'u 2000-3500 TL harcama yapmaktadır.

Öğrencilerin Kapadokya Üniversitesi'ne gelmeden önceki yaşadıkları yerleşim birim türüne bakıldığında yüzde 2.2'si Köyde, yüzde 4.3'ü Kasabada, yüzde 39.1'i İlçede, yüzde 18.5'i İl merkezlerinde ve yüzde 35.9'u büyükșehirlerde yaşamaktadırlar. Kapadokya Üniversitesi'ndeki öğrenimleri sürecinde ise araştırmaya katılanların yüzde 37'si yurtlarda ikamet ederken; yüzde 33.7'si evde arkadaşlarıyla, yüzde 12'si evde yalnız, yüzde 5.4'ü ailesiyle ve yüzde 12'si de diğer şekillerde ikamet etmektedirler.

\section{2. Üniversite ve Üniversitenin Bulunduğu Yerleşim Birimiyle İlgili Faktörler}

Kapadokya Üniversitesi Meslek Yüksekokulunda Okuyan öğrenciler Kapadokya Üniversitesi Mustafapaşa Yerleşkesinde, Mustafapaşa'da ve Ürgüp'te günlük yaşamlarını sürdürmektedirler. Dolayısıyla Türkiye'nin sahil yerleșim birimlerinden gelerek burada yaşayan öğrencilerin yaşam doyumlarının ölçülebilmesi açısından öğrencilerin üniversite 
ve bölgeye ait algılarının tespitine dönük bir ölçek hazırlanmıștır. 46 maddeden oluşan çoklu ölçekten elde edilen verilere dayalı olarak üniversite ve bölgeyle ilgili faktörlerin tanımlanması amacıyla Keşfedici Faktör Analizi gerçekleştirilmiştir. Keşfedici Faktör Analizi, diğer bir ifadeyle Açıklayıcı Faktör Analizi araştırmacının araștırma yaptığı konuyla ilgili olarak değişkenler arasındaki ilişki konusunda herhangi bir fikrinin veya öngörüsünün olmadığı durumlarda değişkenler arasındaki muhtemel ilişkiyi ortaya çıkarmak için yapılır (Çoşkun, Altunışık , Bayraktaroğlu, \& Yıldırım, 2015, s. 266). Dolayısıyla keşfedici faktör analizi daha öncesinde değişkenleri ve bu değişkenlerin oluşturduğu faktörlerin belirlenmediği araștırma konusunda ilk kez gerçekleștirilen ve araştırma konusuyla ilgili değişken ve değişken gruplarının tanımlandığı analizlerdir.

Yapılan faktör analizinde toplam 18 maddenin 5 farklı gruba ayrılabileceği görülmüștür. Maddeler ile ana grup arasında anlamlı $(p=, 000)$ bir fark oluşmuştur. KMO Örneklem Yeterliliği Ölçütü ise 0,786 olarak gerçekleşmiştir. Çok iyi $(0,80-0,90$ arası) olarak değerlendirilebilecek KMO Örneklem Yeterliliği Ölçütüne oldukça yakın olan bu değer veri setinin faktör analizi için iyi düzeyde uygun olduğunu göstermektedir (Kalaycı, 2006 , s. 322). Toplam varyansın yüzde 62.606'sının açıklandığı analizde faktörlere ayrılan 18 maddenin genel güvenilirlik düzeyi $(\alpha), 732$ olarak gerçekleşmiştir (Tablo 1). Bu düzey faktöre ayrılan maddelerin oldukça güvenilir olduğunu göstermektedir (Kayıș, 2006, s. 405)

Tablo 1: Bölge, Şehir ve Üniversiteyle İlgili Algılar

\begin{tabular}{|c|c|c|c|c|c|c|c|}
\hline \multirow{2}{*}{ MADDELER } & \multirow{2}{*}{ A.0 } & \multirow{2}{*}{ SS } & \multirow[b]{2}{*}{1} & \multicolumn{4}{|c|}{ F. Yükü } \\
\hline & & & & 2 & 3 & 4 & 5 \\
\hline \multicolumn{8}{|l|}{ Faktör 1: ÜNIVERSITE } \\
\hline $\begin{array}{l}\text { Okuduğum üniversitesinin yaşam } \\
\text { doyumumu arttırdığını düşünüyorum. }\end{array}$ & 2,3152 & 1,24855 & ,790 & & , 182 & &,- 288 \\
\hline $\begin{array}{l}\text { Üniversitemin bulunduğu şehir } \\
\text { yaşam doyumumu artırlyor. }\end{array}$ & 2,0543 & 1,13258 & ,715 & & ,370 & ,304 & \\
\hline $\begin{array}{l}\text { Üniversitemin bulunduğu } \\
\text { yerleşkeden memnunum. }\end{array}$ & 2,4022 & 1,32648 & ,710 &, 117 & & &,- 199 \\
\hline $\begin{array}{l}\text { Üniversitemin bulunduğu } \\
\text { şehirden memnunum. }\end{array}$ & 2,3913 & 1,29204 & ,702 & ,216 & &,- 203 & ,127 \\
\hline $\begin{array}{l}\text { Üniversitemde çok kulüp olması } \\
\text { yaşam doyumumu artırıyor. }\end{array}$ & 2,1848 & 1,15720 & ,695 & ,279 & & ,158 & \\
\hline $\begin{array}{l}\text { Üniversitemin bulunduğu şehrin } \\
\text { doğasından memnunum. }\end{array}$ & 2,6087 & 1,23107 & ,640 & ,289 & , 149 &,- 264 & \\
\hline $\begin{array}{l}\text { Üniversitemin bulunduğu } \\
\text { yerleşkedeki nüfusun azlığı } \\
\text { yaşam doyumumu artırıyor. }\end{array}$ & 2,5000 & 1,26230 &, 534 & & ,499 & & \\
\hline Aritmetik Ortalama & \multicolumn{7}{|c|}{2,35092} \\
\hline \multicolumn{8}{|l|}{ Faktör 2: YEME-içME } \\
\hline $\begin{array}{l}\text { Kapadokya'da hâkim olan yemek } \\
\text { kültürü hoşuma gidiyor. }\end{array}$ & 2,0000 & 1,22250 & ,129 &, 775 & & & \\
\hline $\begin{array}{l}\text { Kapadokya'da farklı tatlar } \\
\text { deneyebiliyorum. }\end{array}$ & 1,9891 & 1,11429 & ,112 &, 756 & ,235 & & \\
\hline $\begin{array}{l}\text { Dişarıda yemek yiyebileceğim } \\
\text { çok fazla alternatif var. }\end{array}$ & 1,8913 & 1,24439 & , 195 & ,740 & &,- 283 & \\
\hline
\end{tabular}




\begin{tabular}{|c|c|c|c|c|c|c|c|}
\hline \multirow{2}{*}{ MADDELER } & \multirow{2}{*}{ A.0 } & \multirow{2}{*}{ SS } & \multirow[b]{2}{*}{1} & \multicolumn{4}{|c|}{ F. Yükü } \\
\hline & & & & 2 & 3 & 4 & 5 \\
\hline \multicolumn{8}{|l|}{ Faktör 3: YERLi HALK } \\
\hline $\begin{array}{l}\text { Kapadokya'nın turistik bir } \\
\text { mekân olması açık fikirli bir } \\
\text { toplum yaratmaktadır. }\end{array}$ & 3,0870 & 1,34779 & ,201 & ,291 & ,725 & & \\
\hline $\begin{array}{l}\text { Kapadokya halkı, üniversite } \\
\text { kurumlarına olumlu bakmaktadır. }\end{array}$ & 2,8152 & 1,31708 & ,341 & ,375 & ,494 & ,282 & \\
\hline $\begin{array}{l}\text { Kapadokya halkı ile kendimi } \\
\text { sınırlamadan iletişim kurabiliyorum. }\end{array}$ & 2,4130 & 1,17812 &, 120 & ,374 & ,492 &,- 299 & \\
\hline Aritmetik Ortalama & \multicolumn{7}{|c|}{2,7717} \\
\hline \multicolumn{8}{|l|}{ Faktör 4: MIMARI YAPI } \\
\hline $\begin{array}{l}\text { Kapadokya'da bina cephelerinin } \\
\text { basit ve monoton olması } \\
\text { beni olumsuz etkiliyor. }\end{array}$ & 3,4457 & 1,26980 & & &,- 124 & ,862 & \\
\hline $\begin{array}{l}\text { Kapadokya'nın mimari yapısının } \\
\text { ağırlıklı olarak kahverengi ve } \\
\text { sarı renklerden oluşması ruh } \\
\text { halimi olumsuz etkiliyor. }\end{array}$ & 4,0870 & 1,24611 &,- 356 &,- 217 & & ,629 & \\
\hline Aritmetik Ortalama & \multicolumn{7}{|c|}{3,76635} \\
\hline \multicolumn{8}{|l|}{ Faktör 5: ŞEHIR } \\
\hline $\begin{array}{l}\text { Şehrin iklimi mutluluğumu } \\
\text { arttıran bir faktördür. }\end{array}$ & 3,8587 & 1,42645 &,- 175 & & &,- 109 & ,799 \\
\hline İnsanlar yaşadıkları şehirden etkilenir. & 4,3913 & 1,04783 & & & ,154 & & ,705 \\
\hline $\begin{array}{l}\text { Şehrin yer aldığı coğrafi bölge, } \\
\text { orada ikamet etmemde önemlidir. }\end{array}$ & 3,6413 & 1,28029 &, 254 &, 114 &,- 450 &, 141 &, 571 \\
\hline Aritmetik Ortalama & \multicolumn{7}{|c|}{3,96376} \\
\hline Öz değer (Eigenvalues) & & & 3,781 & 2,384 & 1,775 & 1,686 & 1,644 \\
\hline Varyans (\%) & & & 21,005 & 13,242 & 9,859 & 9,364 & 9,136 \\
\hline Toplam Varyans (\%) & & \multicolumn{6}{|c|}{62,606} \\
\hline $\begin{array}{l}\text { Faktör Güvenilirlikleri } \\
\text { (Cronbach's Alpha) }\end{array}$ & & & ,856 & ,756 & ,665 & ,638 &, 514 \\
\hline Genel Güvenilirlik (Cronbach’s Alpha) & & \multicolumn{6}{|c|}{,732 } \\
\hline $\begin{array}{l}\text { KMO Measure of Sampling } \\
\text { Adequacy }\end{array}$ & & \multicolumn{6}{|c|}{,786 } \\
\hline Bartlett's Test of Sphericity & & \multicolumn{6}{|c|}{$X^{2}=581,094 ; d f=153 ; p=, 000$} \\
\hline
\end{tabular}

Araştırmada ilk faktör grubu Kapadokya Üniversitesi'yle ilgili 7 maddeden oluşmaktadır. Bu nedenle bu faktör "üniversite" olarak tanımlanmıștır. Güvenilirlik düzeyi $(\alpha), 856$ olarak gerçekleşen faktörün öz değeri 3,781'dir. Toplam varyansın yüzde 21.005'inin açılklandığı Üniversite faktöründe yer alan maddelerin aritmetik ortalaması 5'li Likert Ölçeğinde 2.350 olarak gerçekleșmiştir. Bu ortalama faktör maddelerinin olumsuz bir değerler aldıklarını göstermektedir. En yüksek faktör yükü (.790) "Okuduğum üniversitesinin yaşam doyumumu arttırdığını düşünüyorum.” maddesinde gerçekleşirken; en düşük faktör yükü (.534) "Üniversitemin bulunduğu yerleşkedeki nüfusun azlığı yaşam doyumumu artırıyor.” maddesinde gerçekleşmiştir (Tablo 1).

Üniversite öğrencilerinin Kapadokya bölgesindeki yemek kültürü ve bulundukları mekanlardaki yemek imkanlarıyla ilgili 3 maddenin oluşturduğu grup "yeme-içme" faktörü olarak tanımlanmıştır. Toplam varyansın yüzde 13.242'sinin açıklandığı "yemeiçme" faktöründe yer alan maddelerin özdeğeri 2.384, güvenilirlik düzeyi ise $(\alpha), 756$ olarak gerçekleşmiştir. Faktörde en yüksek faktör yükü (.775) "Kapadokya'da hâkim olan 
yemek kültürü hoşuma gidiyor." maddesinde gerçekleşirken; en düşük faktör yükü (.740) "Dışarıda yemek yiyebileceğim çok fazla alternatif var." maddesinde gerçekleşmiştir. Maddelerin 5'li Likert Ölçeğinde aldığı değerin aritmetik ortalaması 1.960 olarak gerçekleşmiştir. Bu değer öğrencilerin "yeme-içme" faktöründeki maddelere katılmama yönünde cevaplar verdiklerini göstermektedir (Tablo 1).

Kapadokya bölgesindeki yerel halkın üniversite ve üniversite öğrencilerine yaklaşımıyla ilgili 3 maddenin oluşturduğu grup "yerel halk" faktörü olarak tanımlanmıștır. Özdeğeri 1.775 olan bu faktörün güvenilirlik değeri $(\alpha) .665$ olarak gerçekleşmiştir. Toplam varyansın yüzde 9.859'unun açıklandığı "yerel halk" faktöründe yer alan maddelerin aritmetik ortalaması 2,771 olarak gerçekleşmiştir. 5'li Likert Ölçeğinde alınan bu değer, faktör maddelerine verilen cevapların "ne katılıyorum ne de katılmıyorum" aralığında olduğunu göstermektedir. En yüksek faktör yükü (.725) "Kapadokya'nın turistik bir mekan olması açık fikirli bir toplum yaratmaktadır" maddesinde gerçekleşirken; en düşük faktör yükü (.492) "Kapadokya halkı ile kendimi sınırlamadan iletişim kurabiliyorum" maddesinde oluşmuştur (Tablo 1).

Kapadokya bölgesindeki mimari yapıyla ilgili 2 maddenin olușturduğu faktör "Mimari Yapı" olarak tanımlanmıştır. Bu faktörün güvenilirlik değeri $(\alpha) .638$, özdeğeri ise 1.686 olarak gerçekleşmiştir. Toplam varyansın yüzde 9.364'ünün açıklandığı faktörde en yüksek faktör yükü (.862) "Kapadokya'da bina cephelerinin basit ve monoton olması beni olumsuz etkiliyor" maddesinde; en düşük faktör yükü (.629) ise "Kapadokya'nın mimari yapasının ağırlıklı olarak kahverengi ve sarı renklerden oluşması ruh halimi olumsuz etkiliyor" maddesinde gerçekleșmiştir. Aritmetik ortalaması 3.766 olarak gerçekleşen faktör maddelerini cevaplayıcıların katılıyorum yönünde cevaplandırdığı görülmektedir (Tablo 1).

Öğrencilerin yaşanılan şehirle ilgili algılarının yer aldığı maddelerin 3'ünün oluşturduğu grup "șehir" faktörü olarak isimlendirilmiştir. Toplam varyansın yüzde 9.136'sının açıklandığı bu faktörün özdeğeri 1.644, güvenilirliği $(\alpha) .514$ 'tür. En yüksek faktör yükü (.799) "Şehrin iklimi mutluluğumu artıran bir faktördür" maddesinde, en düşük faktör yükü (.571) ise "Şehrin yer aldığı coğrafi bölge orada ikamet etmemde önemlidir." maddesinde gerçekleşmiştir. "Şehir" faktöründe yer alan maddelerin aritmetik ortalaması 3.963 olarak gerçekleşmiştir (Tablo 1). Bu ortalama faktörde yer alan maddelerin cevaplayıcılar tarafından "katılıyorum" şeklinde cevaplandığını göstermektedir.

\subsubsection{Sosyo-Demografik Değişkenler ve Faktörler Arası Farklar}

Çalışmada araştırmaya katılan öğrencilerin cinsiyeti, aylık harcama miktarları, üniversiteye gelmeden önceki yaşadıkları yerleşim birimi ve üniversite öğrenimleri sürecinde ikamet ettikleri yer ile üniversite öğrenimleri sürecinde üniversite ve üniversitenin bulunduğu şehir ve bölgeyle ilgili algıları arasında gerçekleşen anlamlı farkların ele alınması amacıyla ilgili değişkenler arasında ANOVA ve Bağımız Örneklem T-Testi gerçekleştirilmiştir.

Araștırmaya katılan öğrencilerin cinsiyetleri ile bölge, şehir ve üniversiteye dönük algıların tanımlandığı faktörleri arasında anlamlı bir fark ( $p>, 050)$ bulunamamıștır. Ancak anlamlı bir fark oluşturmamakla birlikte "üniversite", "yeme-içme", "yerli halk", "mimari" ve "şehir" faktörlerinin hepsinde kadınlara ait ortalamaların az bir oranla erkeklere göre daha yüksek olduğu görülmüştür. 
Öğrencilerin aylık harcama miktarları ve öğrencilerin öğrenim sürecindeki ikamet biçimleri (yurt, evde arkadașıyla, evde yalnız, aileyle ve diğer) ile üniversite ve bölge, şehir ve üniversiteye olan algıların tanımlandığı faktörler arasında anlamlı ( $p>.050)$ bir fark oluşmamıştır.

Öğrencilerin üniversite okumaya gelmeden önceki yaşadıkları yerleşim birimi ile "üniversite" faktörü arasında anlamlı $(p=, 034)$ bir fark bulunurken; diğer faktörler açısından anlamlı ( $\mathrm{p}>, 050)$ bir fark oluşmamıştır. Buna göre öğrencilerin üniversiteye gelmeden önce yaşadıkları yerleşim birimi büyüdükçe üniversite faktörünün ortalaması da düşmüştür. Diğer bir ifadeyle üniversiteye gelmeden önce öğrencilerin yaşadığı yerler köyden büyükşehire doğru sıralandığında; yaşanılan yer büyüdükçe "üniversite" faktörüyle ilgili algıları da olumsuzlaşmaktadır.

\subsection{Yaşam Doyumu Ölçeği Doğrulayıcı Faktör Analizi}

Diener (1985) tarafından genç yaş grupları için geliştirilen yaşam doyumu ölçeği (Köker, 1991, s. 41) tek faktörlü bir ölçektir. Diğer bir ifadeyle, tek gizli değişkene sahip bir ölçektir. Dolayısıyla bu araştırmada yaşam doyumu ölçeği aracılığıyla toplanan verilerin ölçek modeline uygunluğunun test edilmesi açısından doğrulayıcı faktör analizi (DFA) gerçekleştirilmiştir. AMOS programı yapısal eşitlik modellemesiyle gerçekleştirilen Yaşam Doyumu DFA'da tek gizli değişken ve 5 madde 0,500'den daha büyük faktör yükleriyle gruplanmıştır. Verilere ait çarpıklık ve basıklık değerleri her bir madde için -2 +2 aralığında gerçekleşmiş ve bu değerler, verilerin normal dağıldığını göstermektedir (Eroğlu, 2006, s. 209). Araştırma verilerinin normal dağılım göstermesi nedeniyle En çok olabilirlik (Maximum Likelihood) hesaplama yöntemi kullanılmıştır. En çok olabilirlik yöntemi yapısal eşitlik modellerinde yaygın olarak tercih edilen bir yöntemdir. Şehribanoğlu (2005) en çok olabilirlik tahminlemesinde modeldeki değişkenlerin gözlem değerlerinin normal dağılım gösterdiği varsayımının olduğunu belirtmektedir (Çınar, 2019, s. 203). Analiz sonucunda ölçekte yer alan her bir maddenin regresyon katsayılarının anlamlı olduğu ve standardize edilmiş regresyon katsayılarının ise (faktör yüklerinin) 0.500'ün üzerinde gerçekleștiği görülmüştür. Buna göre "yaşamım birçok yönüyle idealime yakın" maddesinin regresyon katsayısı 0,92, "yaşamımdan hoşnutum" maddesinin regresyon katsayısı 0,81, "yaşam koşullarım çok iyi” maddesinin regresyon katsayısı 0.78, "şu ana kadar istediğim şeyleri elde edebildim" maddesinin regresyon katsayısı 0,63 ve "yeniden Dünyaya gelseydim yaşamımdan hiçbir şeyi değiştirmezdim" maddesinin regresyon katsayısı 0,57 olarak gerçekleşmiştir. Model uyum değerlerinin daha iyi sonuç vermesi bakımından düzeltme indekslerine bakılmış ve bu indekslerde madde 4 ile madde 5 'in hata varyanslarının birleştirilmesinin yararlı olacağı görülmüştür. Yapılan düzeltme işlemi sonrasında elde edilen model uyum değerleri (CMIN=5.442; $\mathrm{DF}=4$; $\mathrm{CMIN} / \mathrm{DF}=1,360$; RMSEA= ,063; $\mathrm{CFI}=, 994 ; \mathrm{GFI}=, 978$ ) yaşam doyumu modeli ile elde edilen verilerin uyumlu olduğunu göstermektedir. Dolayısıyla bu araștırmada elde edilen veriler yaşam doyumu ölçeği ile uyumluluk göstermektedir. Diğer bir ifadeyle yaşam doyumu ölçeği bu yapılan araştırma ile doğrulanmıştır. 


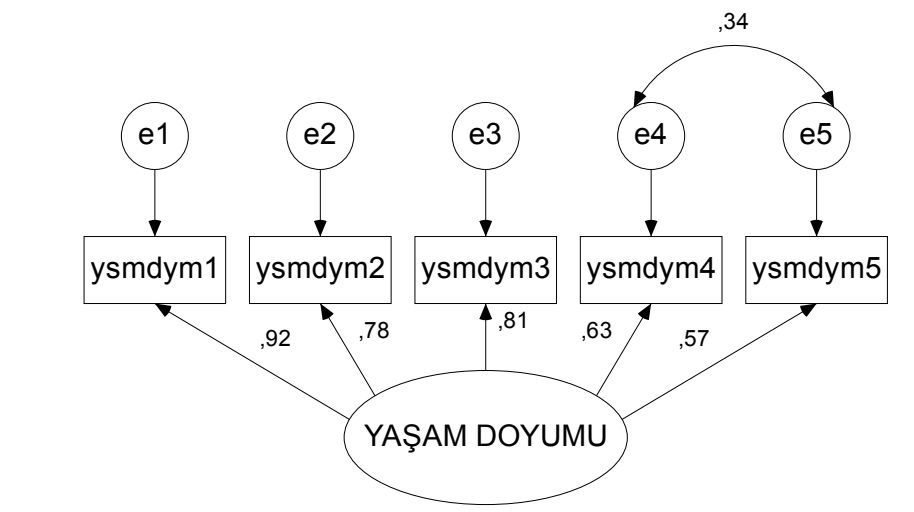

$(C M I N=5.442 ; D F=4 ; C M I N / D F=1,360 ; R M S E A=, 063 ; C F I=, 994 ; G F I=, 978)$

Grafik 1: Yaşam Doyumu DFA Sonuçları.

Yaşam doyumu ölçeğinde yer alan her bir maddenin aritmetik ortalaması incelendiğinde "yaşamım birçok yönüyle idealime yakın" maddesinin ortalaması 3,195, "yaşam koşullarım çok iyi" maddesinin ortalaması 3,228, "yaşamımdan hoşnutum" maddesinin ortalaması 3,478, "şu ana kadar istediğim șeyleri elde edebildim" maddesinin ortalaması 3,271 ve "yeniden Dünyaya gelseydim yaşamımdan hiçbir şeyi değiştirmezdim" maddesinin ortalaması 2,652 olarak gerçekleşmiştir. Cevapların 5’li Likert tipi bir ölçekle alınması nedeniyle araştırmaya katılanların 1, 2, 4 ve 5'inci maddelerde "ne katılıyorum ne de katılmıyorum" yönünde, 3'üncü maddede ise "katılıyorum yönünde cevap verdikleri görülmüştür. Bu bakımdan öğrencilerin yaşamlarından genel anlamda hoşnut oldukları ancak ideal bir hoșnutluk ya da başka bir seçeneğe olan özlem konusunda kararsız oldukları söylenebilir.

\section{4. Öğrencilerin Üniversiteye ve Bölgeye Olan Algılarının Yaşam Doyumlarına Etkisi}

Araştırmada Türkiye'nin sahil bölgelerinden gelerek kırsal bir bölgede üniversite okuyan öğrencilerin yaşam doyumları üzerine etki eden faktörler ele alınmaktadır. Bu bağlamda Diener'in yaşam doyumu ölçeği ve bu çalışmada keşfedici faktör analiziyle öğrencilerin bölge, şehir ve üniversiteye olan algılarının tanımlandığı faktörler arasında çoklu doğrusal regresyon analizi gerçekleştirilmiştir.

Tablo 2: Şehir, Bölge ve Üniversite Algısının Öğrencilerin Yaşam Doyumuna Etkisi

\begin{tabular}{|c|c|c|c|c|}
\hline \multirow{6}{*}{ Yaşam Doyumu } & \multirow{5}{*}{$=$} & \multirow{5}{*}{$-1,056$} & + & ,237 Üniversite $(, 051)$ \\
\hline & & & + & -,135 Yeme - İçme $(, 243)$ \\
\hline & & & + & ,039 Yerli Halk $(, 746)$ \\
\hline & & & + & - ,006 Mimari $(, 955)$ \\
\hline & & & + & , 368 Şehir $(, 000)$ \\
\hline & & & & $R^{2},=, 173 ; F_{(5-86)}=3.588 ; P=, 005$ \\
\hline
\end{tabular}

Analizde öğrencilerin bölge, şehir ve üniversite hakkındaki algılarının tanımlandığı faktörlerin öğrencilerin yaşam doyumlarını etkilediği şeklinde oluşturulan modelin anlamlı $(p=, 005)$ olduğu görülmüştür. Gerçekleştirilen regresyon analizinde Durbin Watson testi sonucu 1.513 olarak gerçekleşmiştir. Durbin Watson katsayısı regresyon analizinde bakılması gereken önemli bir değerdir. Bu değer orta korelasyonun test edilmesinde kullanılmaktadır. Durbin Watson değerinin 1.5 ile 2.5 arasında olması istenir (Öztürk, 2006, s. 264). Analiz sonuçları bölge, şehir ve üniversiteyle ilgili öğrencilerde oluşan algının öğrencilerin yaşam doyumlarının yüzde 17.3'ünü açıkladığını göstermiştir. Dolayısıyla öğrencilerin yaşam doyumlarında olumlu ya da olumsuz yönde gerçekleşecek 
bir değişimin yüzde 17.3 oranında üniversite ve şehirle ilgili algılardaki değişime bağlı olduğu söylenebilir. Üniversite ve şehirle ilgili faktörlerin öğrencilerin yaşam doyumuna etkisine bakıldığında ise "şehir" (VIF=1.013/Tolerans=,987) faktörünün öğrencilerin yaşam doyumları üzerinde anlamlı bir etken olduğu sonucuna ulaşılırken; "üniversite" (VIF=1.488/Tolerans=,672), "yeme-içme" (VIF=1.369/Tolerans=,730), "yerli halk" (VIF=1.506/Tolerans=,664) ve "mimari" (VIF=1.192/Tolerans=,839) faktörlerinin öğrencilerin yaşam doyumları üzerinde anlamlı bir etken olmadığı görülmüştür. $\mathrm{Bu}$ bakımdan şehir faktörüne bağlı olarak öğrencilerde oluşacak bir algıda gerçekleşecek bir birimlik bir artış ya da bir azalış öğrencilerin yaşam doyumlarını pozitif yönlü olarak yüzde 36.8 oranında etkilemektedir. Diğer bir ifadeyle öğrencilerin şehir faktörüyle ilgili algılarında pozitif yönlü bir değişim pozitif yönde, negatif yönlü bir değişim ise negatif yönde öğrencilerin yaşam doyumlarını artırmakta ya da azaltmaktadır.

\section{Sonuç}

Yaşam doyumu bireyin olumlu bir geçmişinin ve umutlu bir geleceğinin önemli göstergelerinden biridir. Bireyin yaşadığı andan aldığı tatmin düzeyi geçmiş ve geleceğiyle hem kendisini hem de çevresini etkilemektedir. Dolayısıyla bireyin yaşam doyumunu ekonomik, sosyal, kültürel, siyasal, özgürlük gibi birçok faktörlerin etkilediği söylenebilir. Bireyin yaşadığı bölge, şehir, ait olduğu kurum da bu etkenlerden biridir. Bu bağlamda Kapadokya Üniversitesi Meslek Yüksekokulunda okuyan ve Türkiye'nin sahil bölgelerinden gelen öğrencilerinin yaşam doyumları üzerinde bulundukları bölgenin, şehrin ve üniversitenin etkisini ele alan bu çalışma geçekleştirilmiştir. Bu çalışmada Diener'in beş maddeden oluşan yaşam doyumu ölçeği kullanılarak öğrencilerin yaşam doyumlarıyla ilgili veriler elde edilmiştir. Ayrıca araştırmada öğrencilerin üniversite, şehir ve bölgeyle ilgili algılarının alt boyutlarıyla ortaya konduğu ayrı bir ölçek geliştirilmiştir.

Gerçekleștirilen Doğrulayıcı Faktör Analizi ile araştırmada elde edilen verilerin Diener'in yaşam doyumu ölçeğiyle uyumlu olduğu ve araștırmanın ikinci bölümünde elde edilen verilerden ise öğrencilerin üniversite, şehir ve bölge ile ilgili algılarının beş faktörde toplanabileceği görülmüştür. Bunlar "üniversite", "yeme-içme", "yerli halk", "mimari yapı" ve "şehir" faktörleridir.

Yapılan analizler araştırma hipotezi 1 ve 5 'te $\mathrm{H}_{1}$ hipotezlerinin kabul edildiğini, araștırma hipotezi 2, 3 ve 4'te ise $\mathrm{H}_{0}$ hipotezlerinin kabul edildiğini göstermiştir. Dolayısıyla araștırma başlığı bakımından temel hipotez olan araştırma hipotezi 1'in $\mathrm{H}_{1}$ hipotezinde belirtildiği gibi öğrencilerin üniversite, şehir ve bölgeyle ilgili algılarının onların yaşam doyumları üzerinde anlamlı bir açıklayıcı olduğu görülmüştür. Açıklama oranı ise yaklaşık yüzde 17 bulunmuştur. Bu nedenle Türkiye'nin sahil bölgelerinden gelerek Kapadokya Üniversitesi Meslek Yüksekokulunda okuyan öğrencilerin yaşam doyumlarının yaklaşık olarak yüzde 17 oranında üniversite, șehir ve bölgeyle ilgili algılarına bağlı olduğu söylenebilir. Üniversite, șehir ve bölgeyle ilgili hangi algı faktörlerinin yaşam doyumu üzerinde anlamlı bir etki oluşturduğu üzerinde durulduğunda ise yalnızca "şehir" faktörünün öğrencilerin yaşam doyumları üzerinde anlamlı ve pozitif yönlü bir etken olduğu sonucuna varılmıştır. Bu oran yaklaşık yüzde 37'dir. Dolayısıyla öğrencilerin "şehir" faktörüyle ilgili algılarında olumlu bir gelişme yaşandığında yaşam doyumları da bu oranla yükselmekte; olumsuz bir gelişme yaşandığında ise aynı oranda yaşam doyumları düşmektedir.

Bu çalışma Türkiye'nin sahil bölgelerinden gelerek Orta Anadolu'da kıraç bir bölgede okuyan öğrencilerin yaşam doyumları üzerinde mekânın etkisini ele almaktadır. Üniversite öğrencilerinin öğrenim amacıyla yaptıkları mekân değișikliğini yaşam doyumu 
üzerinden açıklamaya çalışan bu çalışma, yine bu bağlamda yapılacak çalışmalara bir veri niteliği oluşturmaktadır.

Maddi ve araştırma izni gibi kısıtlar nedeniyle araştırmada Türkiye'nin sahil bölgelerinden gelerek Kapadokya Üniversitesi Meslek Yüksekokulunda Okuyan Öğrenciler örnekleme alınmıştır. Dolayısıyla nicel bir araştırma için daha yüksek sayıdaki örneklemlerle gerçekleştirilecek bir araştırma, mekân ve yaşam doyumu arasındaki etkinin yüksek olduğu ve daha fazla faktör açısından bu etkinin gerçekleştiği sonuçlar ortaya koyabilir. Ayrıca bu çalışmanın bir turizm merkezi olan Kapadokya'daki bir üniversitede yapılması nedeniyle aynı konuda Türkiye'nin iç bölgelerindeki diğer üniversitelerde yapılacak bir araştırmayla mekânın yaşam doyumuna etkisi konusunda daha yüksek oranlarda sonuçların oluşabileceği düşünülebilir.

\section{Bilimsel Etiğe Uygunluk}

$\mathrm{Bu}$ çalışma, Kapadokya Üniversitesi Bilimsel Araştırmalar ve Yayın Etiği Kurulu'nun 1.04.2019 tarihli toplantısında görüşülmüş ve gerçekleştirilmesinde etik ve bilimsel sakınca bulunmadığına oy birliği ile karar (2019.03) verilmiştir.

\section{Notlar}

1 Weltbild sözcüğü bireyin içerisinde bulunduğu dünyayı kendi öznel algısı çerçevesinde değerlendirdiğini ifade etmektedir (Duden Sözlük).

\section{Kaynakça}

Argyle, M. (2001). The Psychology of Happiness. 3 14, 2020 tarihinde https://books.google.com.tr/books?redir_esc=y\&hl=tr\&id=tVWzAQA $\mathrm{AQBAJ} \& \mathrm{q}=$ satisfaction\# $\mathrm{v}=$ snippet $\& \mathrm{q}=$ satisfaction\& $\mathrm{f}=$ false adresinden alınd $\mathrm{l}$

Csikszentmihalyi, M. (2005). Akış: Mutluluk Bilimi. (S. Akbaş, Çev.) İstanbul: HYB Yayıncılık. Çınar, Ö. (2019). Yapısal Eşitlik Modeli Örnek Bir Uygulama. İstanbul: Hiperyayın.

Çoşkun , R., Altunıșık , R., Bayraktaroğlu, S., \& Yıldırım, E. (2015). Sosyal Bilimlerde Araştırma Yöntemleri. Sakarya: Sakarya Kitabevi.

Duden Sözlük. (tarih yok). 3 30, 2020 tarihinde https://www.duden.de/rechtschreibung/ Weltbild adresinden alındı

Eroğlu, A. (2006). Çok Değişkenli İstatistik Tekniklerinin Varsayımları. Ş. Kalaycı içinde, SPSS Uygulamalı Çok Değişkenli İstatistik Teknikleri (s. 207-233). Ankara: Asil Yayın Dağıtım.

Kalaycı, Ș. (2006). Faktör Analizi. Ş. Kalaycı içinde, SPSS Uygulamalı Çok Değişkenli İstatistik Teknikleri (s. 321-331). Ankara: Asil Yayın Dağıtım.

Kaya, İ. (2014). Coğrafi Düşüncenin Değişimi ve Paradigmalar. Y. Arı, \& İ. Kaya içinde, Coğrafya Araştırma Yöntemleri (s. 19-49). İstanbul: Coğrafyacılar Derneği.

Kayış, A. (2006). Güvenilirlik Analizi. Ş. Kalaycı içinde, SPSS Uygulamalı Çok Değişkenli Istatistik Teknikleri (s. 403-424). Ankara: Asil Yayın Dağıtım.

Kelly, G. (2003). A Brief Introduction Personal Construct Theory. International Handbook of Personal Construct Psychology (s. 3-20). içinde 3 14, 2020 tarihinde https:// www.infoamerica.org/documentos_pdf/kelly02.pdf adresinden alındı 
Köker, S. (1991). Normal ve Sorunlu Ergenlerin Yaşam Doyumu Düzeyinin Karşılaştırılması. Ankara: Ankara Üniversitesi Sosyal Bilimler Enstitüsü Yayınlanmamış Yüksek Lisans Tezi.

Kurtulmuş, K. (2006). Araştırma Yöntemleri. İstanbul: Türkmen Kitabevi.

Myers, D. (1993). The Pursuit of Happiness: Discovering the Pathway to Fulfillment, WellBeing and Enduring Personal Joy. New York: Avon Books.

Myers, D., \& Diener, E. (1995). Who is happy? Psychological Science, 6(1), 10-19.

Öztürk, E. (2006). Çoklu Doğrusal Regresyon Modeli. Ş. Kalaycı içinde, SPSS Uygulamalı Çok Değişkenli İstatistik Teknikleri (s. 259-269). Ankara: Asil Yayın Dağıtım.

Seligman, M. (2012). The new era of positive psychology. TedEx Talk: https://www.youtube. com/watch?v=rg_28_11Kjw adresinden alındı

Tutar, H. (2018). Davranış Bilimleri Kavramlar ve Kuramlar. Ankara: Seçkin Yayıncılık. 


\section{The Effect of Change of Place Between the Dilemma of Coast and Rural Area on Students' Life Satisfaction: The Case of Cappadocia Vocational High School}

Hasan Güllüpunar (Prof. Dr.)

Merve Özdemir (Lect.)

\section{Extended Abstract}

Life satisfaction is one of the essential indicators of the individual's positive past and hopeful future. The level of comfort that the individual derives is affected by both their past and the environment in which they live. Therefore, it can be said that many factors, such as economic, social, cultural, political freedom, affect the life satisfaction of the individual. The region where the individual lives, the city and the institution to which he belongs is one of these factors. In this context, this study was carried out at the Cappadocia University Vocational School, a region with distinct physical and climatic characteristics, and addresses the impact of the area, city and university on the life satisfaction of students coming from the coastal areas of Turkey. In the study, data related to students' life satisfaction were obtained by using Diener's five-item life satisfaction scale. In addition, a separate scale was developed in order to determine students' perceptions of the region, city and university with their sub-dimensions.

Confirmatory Factor Analysis performed showed that the data obtained in the study were compatible with Diener's life satisfaction scale. From the data obtained in the second part of the scale, it was concluded that the perceptions of students about the region, city and university can be gathered in five factors by making exploratory factor analysis. These factors are "university", "eating and drinking", "local people", "architectural structure" and "city" factor.

The life satisfaction scale developed by Diener (1985) for young age groups is a single factor scale. Confirmatory factor analysis (CFA) was applied to test the suitability of the data collected through the life satisfaction scale to the scale model. The satisfaction of life, which is realized with the structural equation modelling in the AMOS program, shows that the regression coefficients of each item in the CFA are significant and the standardized regression coefficients (factor loads) are above 0.500. Model fit values (CMIN $\neg=5.442$; $\mathrm{DF}=4 ; \mathrm{CMIN} / \mathrm{DF}=1,360 ; \mathrm{RMSEA}=, 063$; $\mathrm{CFI}=$, 994; GFI =, 978) show that the data obtained in the research are compatible with the life satisfaction model. Therefore, the data obtained in this study show compatibility with the life satisfaction scale.

When the arithmetic means of each item in the life satisfaction scale was examined, the following results were obtained; The average of the item "my life is close to my ideal in many aspects" is 3,195 , The average of the "my living conditions are very good" item is 3,228 . The average of the item "I am satisfied with my life" is 3,478 . The average of the item "I have been able to get what I want so far" is 3,271 . The average of the item "If I were born again, I would not change anything from my life" is 2,652. As the answers were obtained with a 5-point Likert type scale, it was seen that the participants responded in the "neither agree nor disagree" items in the 1, 2, 4 and 5 intervals, and in the 3rd article "I agree". 
Students studying at the Cappadocia University Vocational School continue their daily lives at the Mustafapaşa Campus, Cappadocia University, Mustafapaşa and Ürgüp. Therefore, a second scale was prepared to determine students' perceptions of the university and the region to measure the life satisfaction of students living here, who have come from the coastal areas of Turkey. Based on the data obtained from multiple scales consisting of 46 items, Exploratory Factor Analysis was carried out to identify factors related to university, city and region. Exploratory factor analysis is the first analysis performed on the research in which the variables and the factors created by these variables were not determined. And Discovery factor analysis is an analysis in which the variable and variable groups related to the research subject are defined.

In the exploratory factor analysis, it was seen that a total of 18 items can be divided into five different groups. There was a significant difference $(p=, 000)$ between the items and the main group. The KMO Sample Sufficiency Criterion was 0,786 . This value indicates that the data set is well suited for factor analysis. In the analysis, in which 62.606 per cent of the total variance was explained, the general reliability level $(\alpha)$ of the 18 items devoted to the factors was 732. This level shows that the items allocated to the factor, according to the literature, are very reliable.

The first-factor group in the study consists of 7 items related to Cappadocia University. For this reason, this factor has been defined as "university". Regarding the factor, the reliability level of which was $(\alpha) 856$; The eigenvalue of this factor is 3.781. The arithmetic mean of the items in the University factor, where 21.005 per cent of the total variance was explained, was 2.350 on the 5-point Likert Scale.

The group consisting of 3 items related to the food culture of the university students in the Cappadocia region and the dining possibilities in their places was defined as the "eatingdrinking" factor. The eigenvalue of the items in the "eating-drinking" factor, where 13,242 per cent of the total variance was explained, was 2,384, and the reliability level was $(\alpha)$ 756. The arithmetic mean of factor items was realized as 1.960 . This value shows that students responded not to participate in the items in the "eating and drinking" factor.

The group consisting of 3 items related to the approach of local people to university and university students in the Cappadocia region has been defined as "local people" factor. The reliability value of this factor with an eigenvalue of 1,775 was $(\alpha)$.665. The arithmetic mean of the items in the "local people" factor, where 9,859 per cent of the total variance was explained, was 2,771 . This value shows that the answers given to the factor items are in the range of "neither agree nor disagree".

The factor consisting of 2 items related to the architecture of Cappadocia has been defined as "Architectural Structure". The reliability value of this factor $(\alpha)$ was 638 , and its eigenvalue was 1.686. The arithmetic mean of the items in the factor in which 9.364 per cent of the total variance was explained has been 3.766. This value shows that the factor items answered in the agree range.

The group consisting of 3 items of students' perceptions about the city in which they live was named as the "city" factor. The eigenvalue of this factor, which explains 9.136 per cent of the total variance, is 1.644 , and its reliability $(\alpha)$ is 514 . The arithmetic mean of the items in the "city" factor was 3,963. It shows that the items in this average factor are answered as "I agree" by the respondents. 
In the study, regression analysis was carried out between the life satisfaction values of students and the factors that constitute their perceptions about university, city and region. These analyzes showed that students' perceptions about university, city and region are a significant explanatory on their life satisfaction. The disclosure rate is about 17 per cent. Therefore, the life satisfaction of students coming from the coastal regions of Turkey and studying at the Cappadocia University Vocational School depends on their perceptions about university, city, and region by approximately 17 per cent. When it was focused on which perception factors related to university, city and region had a significant effect on life satisfaction, it was concluded that only the "city" factor was a significant and positive factor on students' life satisfaction. This rate is about 37 per cent. Therefore, when there is a positive development in students' perceptions about the "city" factor, their life satisfaction increases in parallel with this rate; when a negative event is experienced, the life satisfaction decreases at the same rate.

This study examines the effect of the place on the life satisfaction of students who come from the coastal regions of Turkey and study in a barren area in Central Anatolia. In the subsequent studies, it is possible to deepen the subject by investigating how the space change that university students have to make for their education has an impact on their life satisfaction with different samples of space.

Keywords: Life Satisfaction, Happiness, University, Cappadocia University. 